\title{
Article \\ Combined Radionuclide Therapy and Immunotherapy for Treatment of Triple Negative Breast Cancer
}

\author{
Alyssa Vito ${ }^{1,+}\left(\mathbb{D}\right.$, Stephanie Rathmann ${ }^{2,+}{ }^{,}$Natalie Mercanti ${ }^{2}$, Nader El-Sayes ${ }^{1}$, Karen Mossman ${ }^{1, *(D)}$ \\ and John Valliant ${ }^{2}$ * \\ 1 Department of Medicine, McMaster Immunology Research Centre, McMaster University, \\ Hamilton, ON L8S 4K1, Canada; vitoar@mcmaster.ca (A.V.); elsayesn@mcmaster.ca (N.E.-S.) \\ 2 Department of Chemistry and Chemical Biology, McMaster University, Hamilton, ON L8S 4K1, Canada; \\ rathmasm@gmail.com (S.R.); mercanne@mcmaster.ca (N.M.) \\ * Correspondence: mossk@mcmaster.ca (K.M.); valliant@mcmaster.ca (J.V.) \\ + The authors contributed equally to this publication.
}

Citation: Vito, A.; Rathmann, S.;

Mercanti, N.; El-Sayes, N.; Mossman,

K.; Valliant, J. Combined

Radionuclide Therapy and Immunotherapy for Treatment of Triple Negative Breast Cancer. Int. J. Mol. Sci. 2021, 22, 4843.

https://doi.org/10.3390/ijms22094843

Academic Editor: Peter C. Hart

Received: 8 April 2021

Accepted: 1 May 2021

Published: 3 May 2021

Publisher's Note: MDPI stays neutral with regard to jurisdictional claims in published maps and institutional affiliations.

Copyright: (C) 2021 by the authors. Licensee MDPI, Basel, Switzerland. This article is an open access article distributed under the terms and conditions of the Creative Commons Attribution (CC BY) license (https:/ / creativecommons.org/licenses/by/ $4.0 /)$.
Abstract: Triple negative breast cancer (TNBC) is an aggressive subtype of the disease with poor clinical outcomes and limited therapeutic options. Immune checkpoint blockade (CP) has surged to the forefront of cancer therapies with widespread clinical success in a variety of cancer types. However, the percentage of TNBC patients that benefit from CP as a monotherapy is low, and clinical trials have shown the need for combined therapeutic modalities. Specifically, there has been interest in combining CP therapy with radiation therapy where clinical studies primarily with external beam have suggested their therapeutic synergy, contributing to the development of antitumor immunity. Here, we have developed a therapeutic platform combining radionuclide therapy (RT) and immunotherapy utilizing a radiolabeled biomolecule and CP in an E0771 murine TNBC tumor model. Survival studies show that while neither monotherapy is able to improve therapeutic outcomes, the combination of RT + CP extended overall survival. Histologic analysis showed that $\mathrm{RT}+\mathrm{CP}$ increased necrotic tissue within the tumor and decreased levels of F4/80+ macrophages. Flow cytometry analysis of the peripheral blood also showed that RT + CP suppressed macrophages and myeloid-derived suppressive cells, both of which actively contribute to immune escape and tumor relapse.

Keywords: triple negative breast cancer; immunotherapy; immune checkpoint therapy; radionuclide therapy

\section{Introduction}

Breast cancer is the most common cancer among women worldwide, accounting for more than two million new cases and 600,000 deaths annually [1]. Triple negative breast cancer (TNBC) accounts for $10-20 \%$ of all breast cancers, presents a higher risk in women under the age of 40 , demonstrates substantial tumor heterogeneity, and is often identified as being high grade [2]. TNBC patients routinely undergo extensive, highly toxic treatment regimens and have the highest risk of relapse amongst all breast cancer types [3,4]. Furthermore, recently approved therapies for TNBC are limited (olaparib, atezolizumab, and sacituzumab-govitecan) and only benefit 10-20\% of patients, highlighting the need for improved therapies for TNBC patients. To this end, a deeper understanding of the immune landscape in TNBC patients is required to develop novel, effective therapies.

Recent years have seen the emergence of immunotherapies in both preclinical and clinical development, revolutionizing the way we think about treating cancer patients. One such therapy, immune checkpoint blockade (CP), uses antibodies to block inhibitory pathways on immune cells and has shown widespread clinical success with durable cures across a variety of cancer types [5,6]. However, the percentage of patients that respond to $\mathrm{CP}$ is low, and even those patients who initially display tumor regression often succumb to 
relapsed disease [5,7]. As the field of immuno-oncology continues to grow, so too does our understanding of immunotherapies and the challenges associated with achieving durable and complete responses to treatment. In an effort to combat clinical barriers to CP efficacy, there has been an emergence of new paradigms incorporating traditional therapies into immunotherapy regimens [8-10].

Radiation therapy has been a mainstay treatment for many forms of cancer since the late 1800s. Historically, radiation has been thought to work solely through direct contactbased killing, but there has long been the postulation of immune involvement through the hypothesis of the abscopal effect [11]. The abscopal effect occurs when an irradiated tumor initiates a cascade of events with the release of damage-associated molecular patterns (DAMPs) such as high mobility group box 1 (HMGB1), adenosine triphosphate (ATP), and heat shock proteins (HSPs). These DAMPs act on receptors that are expressed on dendritic cells (DCs), leading to antigen presentation, tumor-specific killing from cytotoxic $\mathrm{T}$ cells, and ultimately anti-tumor activity (Figure 1). The abscopal effect was first clinically documented in 1953 [12], but interest waned with rare occurrences noted and difficulties in recapitulating the phenomenon in preclinical models. Now, in the era of immunotherapy, there is a much deeper understanding of the immune system and the interplay of cells in the tumor microenvironment (TME), and the abscopal effect has once again been brought to the forefront of oncologic research.

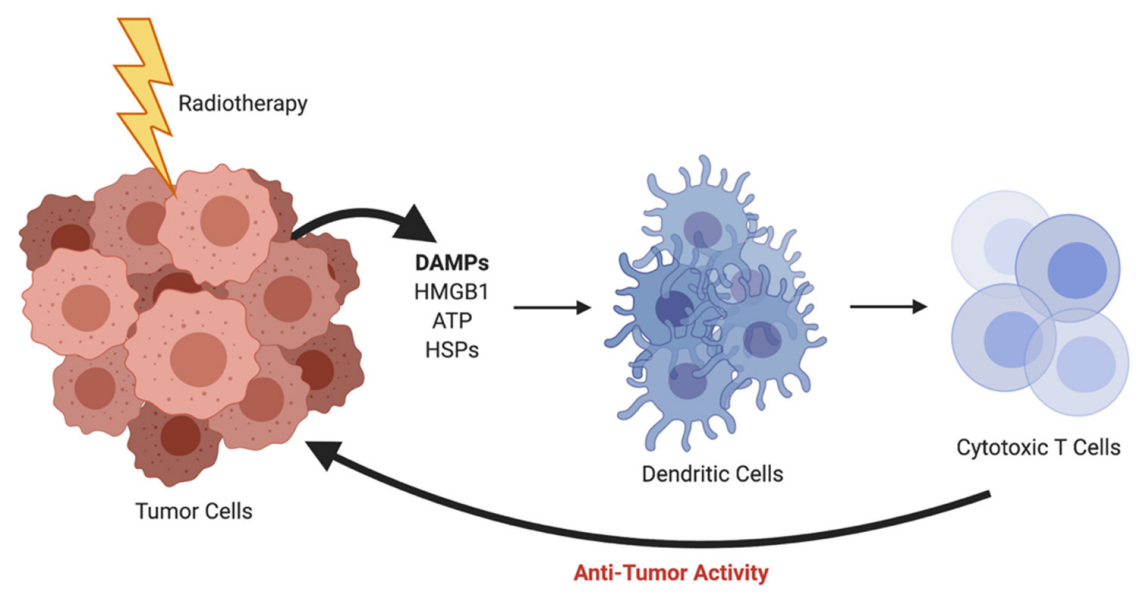

Figure 1. Radiotherapy-induced abscopal effect resulting in anti-tumor activity. ${ }^{*}$ Created using BioRender.com.

Clinical studies have shown that the combination of radiotherapy and immunotherapy synergizes for enhanced anti-tumor activity and improved prognostic outcomes [13-15]. In a phase I clinical trial, patients with metastatic or nonresectable melanoma tumors were treated with anti-CTLA-4 and anti-PD-1 checkpoint antibodies, and a small cohort of patients was also given radiation therapy [15]. This study noted a significant improvement in overall survival percentages in the patient population receiving the dual therapy. Similarly, in a phase II clinical trial, patients with metastatic TNBC (mTNBC) were treated with anti-PD-1 checkpoint antibodies and fractionated external beam radiation therapy [16]. The overall response rate of the patients was $17.6 \%$ with three responders achieving a $100 \%$ reduction in tumor volume outside of the irradiated field. It is important to note that the patients enrolled in the study were unselected for PD-L1 expression and had failed previous first-line therapies.

Here, we outline a therapeutic platform using cytotoxic radiation to sensitize otherwise non-responsive tumors to CP. In particular, we chose to investigate whether continuous cell irradiation, through the use of internal radionuclide therapy (RT), would synergize with dual anti-CTLA-4 and anti-PD-L1 checkpoint therapy. In order to maximize and better control the radiation dose to the tumor, we used intratumoral delivery of the beta emitter, lutetium-177, linked to a biomolecule. Albumin, an abundant blood protein, was used as a 
biocompatible protein anchor to prolong retention of the radionuclide in the tumor. With respective to potential translation, intratumoral injections of albumin radiopharmaceuticals for sentinel node imaging in breast cancer are routinely performed in the clinic [17], while materials labeled with beta emitting isotopes are routinely being delivered in a similar manner for liver cancers.

\section{Results}

\subsection{Tunable Platform for Intratumoral Administration of Radiotherapeutic}

Due to the rich history and proven track record in medical practice, we chose to use albumin as the protein anchor to prolong the retention of the radionuclide within the TME and provide greater control over the administered dose when compared to intravenous (iv) administration [18-20]. To increase the versatility of our platform and ensure that protein integrity is maintained during synthesis, bovine serum albumin (BSA) was first functionalized with trans-cyclooctene (TCO). Then, this TCO-BSA conjugate can undergo a rapid, room temperature inverse electron-demand Diels-Alder (IEDDA) reaction in which the TCO moiety forms a covalent linkage with its coupling partner, a tetrazine, which in this case is radiolabeled with lutetium-177 (Figure 2). This type of two-step functionalization minimizes the risk of a non-specific binding interaction of the radionuclide with BSA. To prepare TCO-BSA, BSA was combined with a TCO-NHS ester, and the mixture was allowed to incubate overnight at room temperature. TCOBSA was purified by dialysis, and the conjugation was confirmed by matrix-assisted laser desorption ionization mass spectrometry (MALDI-MS; Figure S1). The tetrazine was synthesized as previously described [21], and the radiolabeled product was produced by adding [177Lu] $\mathrm{LuCl} 3$ (Figure 3) at $60^{\circ} \mathrm{C}$ for $5 \mathrm{~min}$, resulting in a radiochemical yield of $>99 \%$. The radiolabeled small molecule was incubated with TCO-BSA for ten minutes at room temperature, followed by purification using a high molecular weight spin filter. The resultant radiochemical yield was $46 \pm 5 \%$ based on the amount of activity isolated from the spin filter.

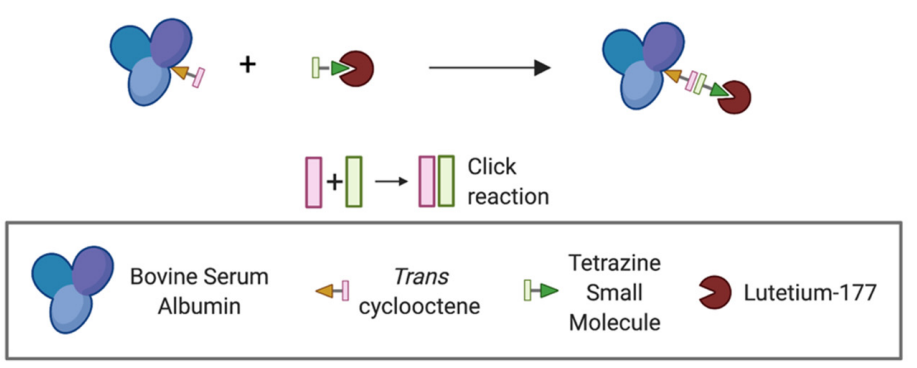

B

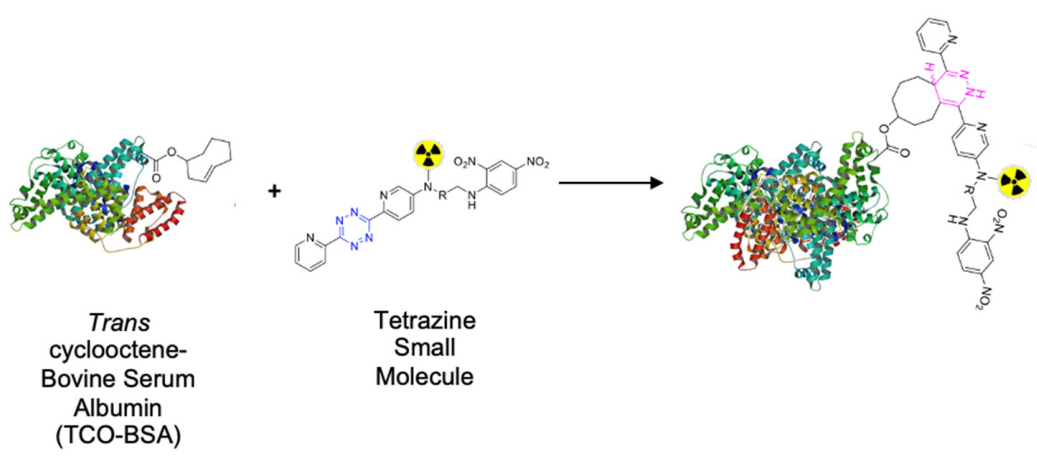

Figure 2. Schematic representation showing the inverse electron-demand Diels-Alder reaction between the trans-cyclooctene and tetrazine-based moieties. (A) Simplified schematic of the overall conjugation and labeling strategy. ${ }^{*}$ Created using BioRender.com. (B) Schematic showing the key functional groups used to label albumin. 


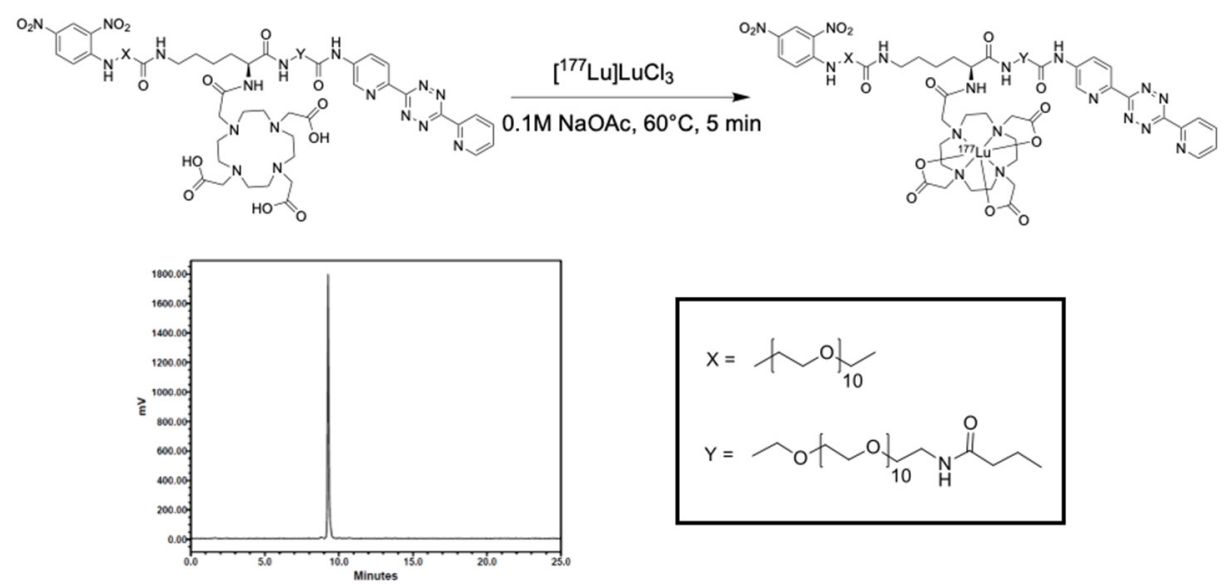

Figure 3. Radiolabeling scheme and radio-HPLC chromatogram of the tetrazine small molecule labeled with lutetium-177.

\subsection{RT Immobilizes in the Tumor Microenvironment}

To evaluate the spatial distribution of the compound within the tumor, qualitative autoradiography studies were performed. Subcutaneous E0771 tumors were grown in C57/B16 mice. Mice were treated with a single intratumoral injection of RT when palpable tumors arose (12 days after implantation), and groups of mice were sacrificed at 24, 72, and $120 \mathrm{~h}$ (Figure 4). These images revealed that the compound was able to distribute well throughout the tumor after a single injection, which is evident out to $120 \mathrm{~h}$. To quantitatively evaluate the long-term retention of the RT in the tumor as well as to assess uptake in nontumor tissues, biodistribution studies were performed with a direct comparison between intratumoral and intravenous administration. RT delivered intratumorally showed high retention in the tumor out to $120 \mathrm{~h}$ as well as high tumor to non-tumor ratios, which are ideal for therapy (Figure S2a, Table S1, $\mathrm{n}=3$ ). As expected, intravenous administration of the RT resulted in poor tumor retention and high uptake in non-tumor tissues (Figure S2b, Table S2, $\mathrm{n}=3$ ).

\subsection{Radiotherapy Results in Improved Prognostic Outcomes}

While radionuclide therapy may be administered as a single or fractionated dose in the clinic, studies suggest improved therapeutic efficacy and enhanced antitumor immunity with fractioned regimens, employing intratumoral injections of as little as $2 \mathrm{MBq}$ per dose in murine xenograft models [22-25]. In an effort to determine the most efficacious dosing regimen for our RT, dose optimization studies were performed. C57/Bl6 mice bearing E0771 subcutaneous tumors on the left flank were treated with RT intratumorally and monitored for overall survival. Preliminary studies utilized a two-dose regimen, with single doses up to $0.74 \mathrm{MBq}$ (Figure S3). This range of radioactivity was insufficient to slow tumor progression, and therefore, the maximum dose was increased to $3.33 \mathrm{MBq}$ and administered as a single dose to monitor host toxicity and tolerability (Figure S4). Mice tolerated treatment well with no acute toxicity seen. Moving to multi-dosing to promote improved efficacy and sustained tumor regression, two doses, with doses ranging from 0 to 4.44 $\mathrm{MBq}$, were given five days apart. This regimen resulted in delayed tumor progression and improved survival outcome (Figure 5). 


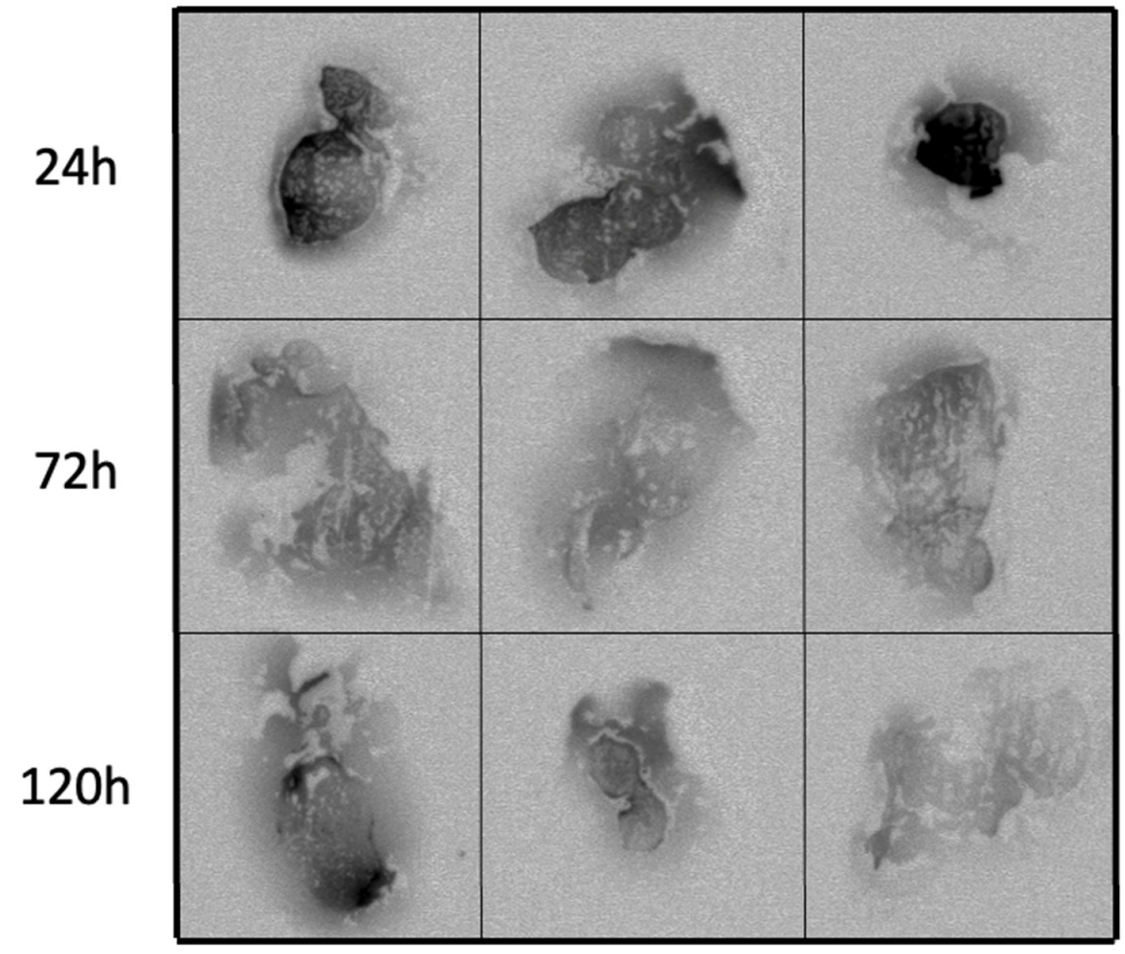

Figure 4. Autoradiography of tumors treated with a single intratumoral injection of RT shows distribution in the TME. C57/B16 mice bearing subcutaneous E0771 tumors were treated with a single intratumoral dose of RT (0.15-0.30 MBq). Mice were sacrificed at 24, 72, and $120 \mathrm{~h}$ after treatment, and tumors were harvested and flash frozen for autoradiography. Each image represents a slice of an individual tumor. The darker the area, the more radioactive decay that was detected in that area.

A
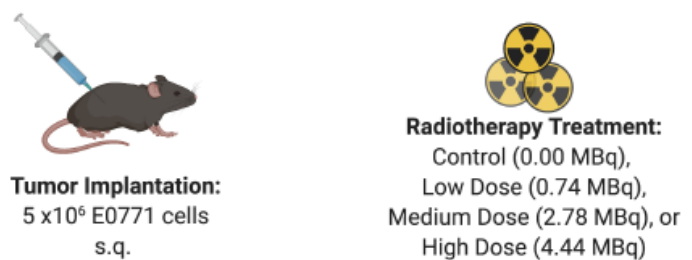

$5 \times 10^{6} \mathrm{E} 0771$ cells

High Dose (4.44 MBq)

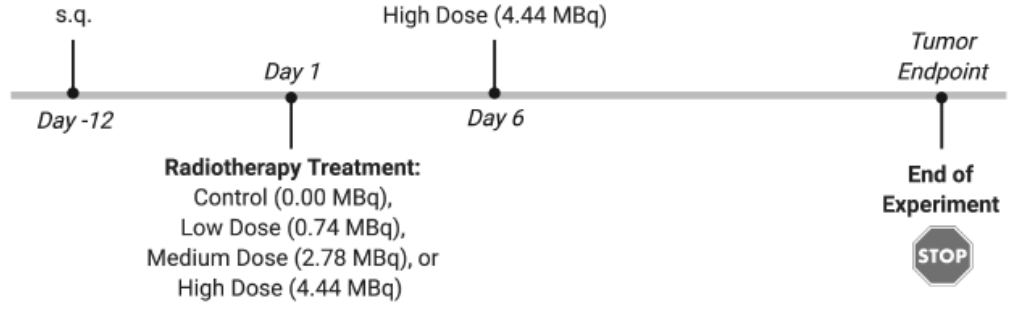

High Dose (4.44 MBq)

Figure 5. Cont. 
B
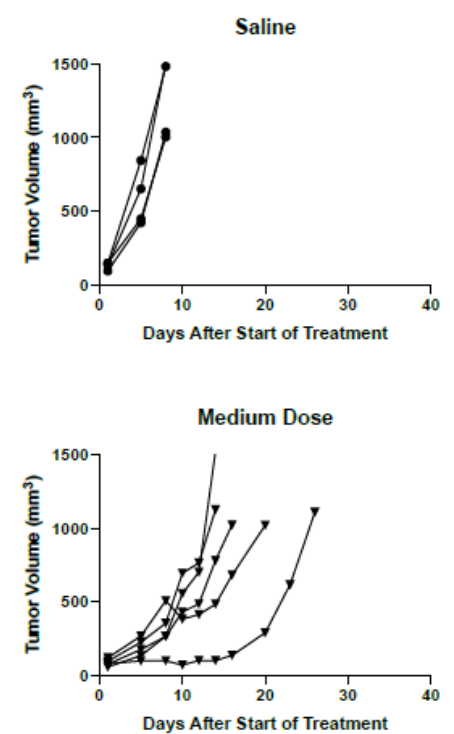

Control

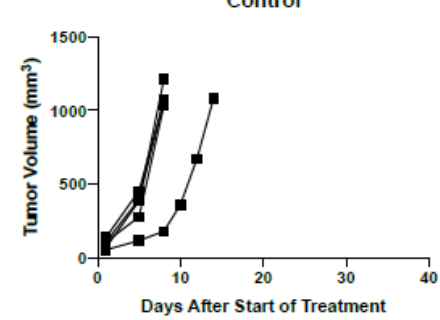

High Dose

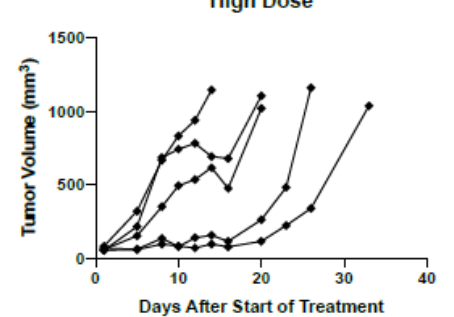

Low Dose

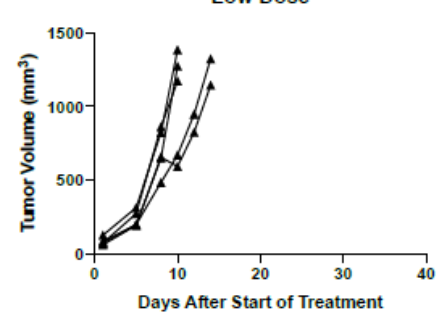

C

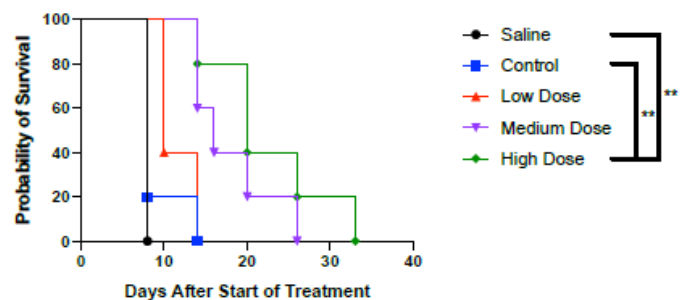

Figure 5. Two administrations of the highest dose RT improved survival outcomes. (A) C57/B16 mice bearing subcutaneous E0771 tumors on the left flank were treated with PBS, control (non-radioactive compound), low dose (0.74 MBq), medium dose (2.78 MBq), or high dose (4.44 MBq) on days 1 and 6. ${ }^{*}$ Created using BioRender.com. (B) Tumor volumes were measured every 2-3 days from the start of treatment until mice reached endpoint. Each line represents an individual mouse within the group. (C) Kaplan-Meier survival curves of each group. ${ }^{* *} p<0.01$.

\section{4. $R T+C P$ Improves Overall Survival in Tumor-Bearing Mice}

As CP continues to gain traction as a viable therapeutic option, using PD-L1 expression as a predictive biomarker has become more commonplace. TNBC tumors do indeed express PD-L1 [26,27]; however, the expression is low, and it is not homogenously distributed throughout the tumor, but rather found in focal areas in a small proportion of cancer cells [28]. Further to this, clinical trials have reported both the efficiency and necessity of combined therapeutic modalities, as TNBC patients often have short-lived responses to CP on its own [29]. Based on our preliminary studies, we hypothesized that high-dose RT is capable of sensitizing tumors to CP. Survival studies were performed with the addition of dual CP targeting the non-redundant pathways of cytotoxic T-lymphocyte antigen 4 and programmed death ligand-1 (with anti-CTLA4 and anti-PD-L1 antibodies, respectively). While neither control (non-radioactive TCO-BSA), RT alone, CP alone, or vehicle control + $\mathrm{CP}$ showed therapeutic efficacy, the combination of RT + CP resulted in greatly improved overall survival (Figure 6). Mice tolerated treatments well with no toxicity seen. 
A

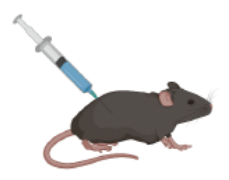

Tumor Implantation: $5 \times 10^{6}$ E0771 cells s.q.

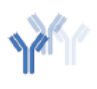

Checkpoint Treatment: $200 \mu \mathrm{g}$ anti-PDL1 $+200 \mu \mathrm{g}$ anti-CTLA-4, i.p.

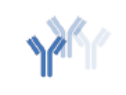

Checkpoint

Treatment:

$200 \mu \mathrm{g}$ anti-PDL1 $+200 \mu \mathrm{g}$ anti-CTLA-4, i.p.

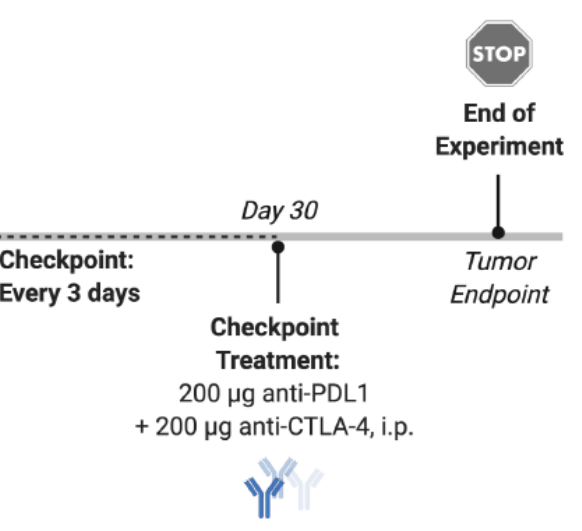

B

PBS

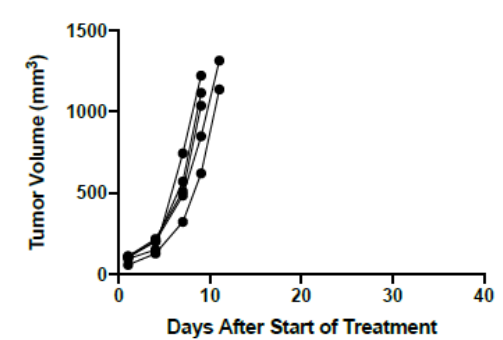

RT

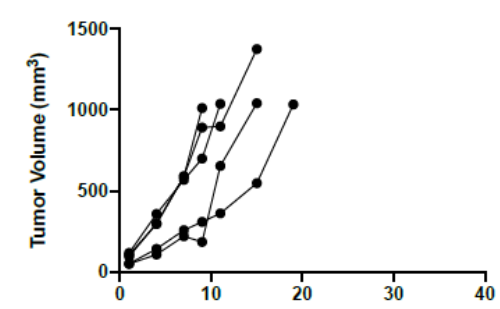

Days After Start of Treatment

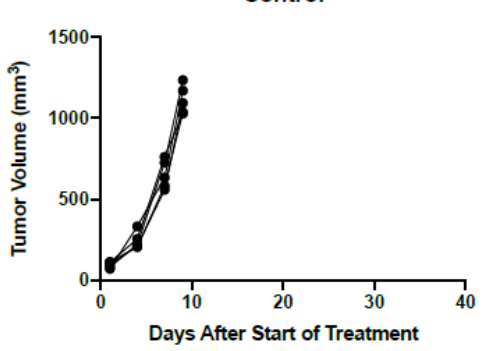

Control + $\mathrm{CP}$

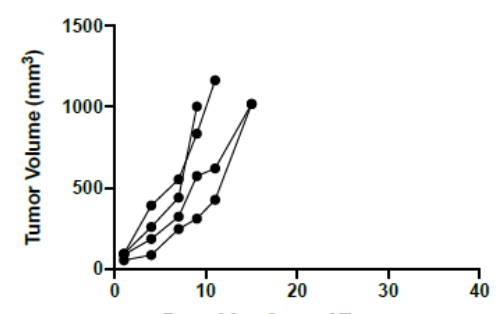

Days After Start of Treatment
CP

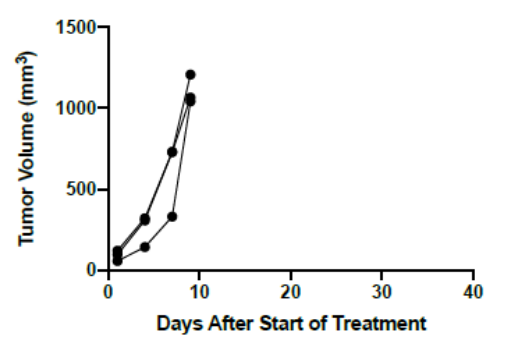

$\mathrm{RT}+\mathrm{CP}$

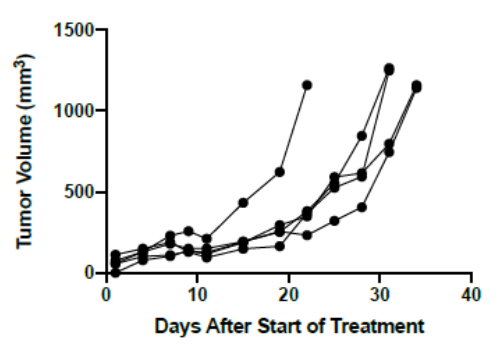

C

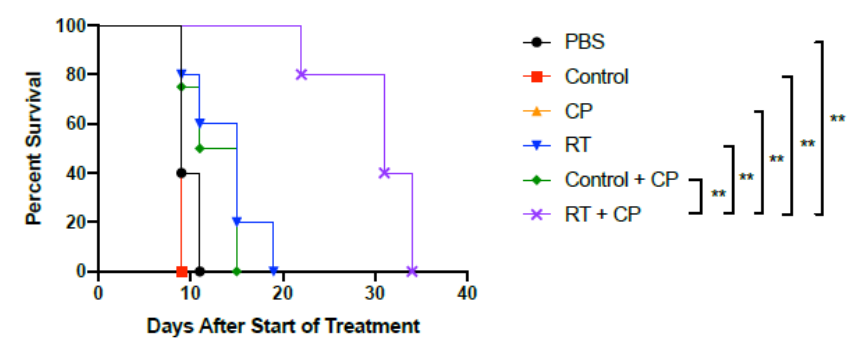

Figure 6. $\mathrm{RT}+\mathrm{CP}$ significantly improves overall survival. (A) C57/B16 mice bearing E0771 tumors were treated with PBS, control, CP (anti-CTLA4 and anti-PD-L1), RT, control + CP or RT + CP. *Created using BioRender.com. (B) Tumor volumes were measured every 2-3 days from the start of treatment until mice reached endpoint. Each line represents an individual mouse within the group. (C) Kaplan-Meier survival curves of each group. ${ }^{* *} p<0.001$. 


\subsection{Radiotherapy + CP Increases TILs in Otherwise Immune-Bare Tumors}

To further investigate the impact of each component of our therapy to the TME, histologic assessment was performed. Tumors were harvested on day 7 from mice treated with PBS, control, CP, RT, control $+\mathrm{CP}$, and RT $+\mathrm{CP}$. Analysis of whole tumor sections harvested and stained with hematoxylin and eosin (H\&E) shows that mice treated with PBS or the control compound have large tumors with many multi-nucleated cells, suggesting rapid cellular division. Mice treated with $\mathrm{CP}$, $\mathrm{RT}$, or control $+\mathrm{CP}$ present with pockets of necrosis and many multi-nucleated cells surrounding these areas, suggesting that although these therapies may induce acute necrosis in areas of the tumor, these mice still have rapid tumor kinetics and disease progression. As expected from survival study outcomes, tumors harvested from mice that were treated with RT $+\mathrm{CP}$ present with increased necrosis and shrinking cellular structures, which was likely a direct result of their response to therapy.

Tumors were further stained with CD4, CD8, and F4/80 to assess immune cell infiltrates in the tumor. Mice treated with PBS or the control compound present with moderate levels of $\mathrm{CD}^{+}$and $\mathrm{CD} 8^{+}$cells with densely populated areas of $\mathrm{F} 4 / 80^{+}$macrophages. Mice treated with $\mathrm{CP}$ therapy have increased levels of $\mathrm{CD} 4^{+}$and $\mathrm{CD} 8^{+}$cells and substantial increases of $\mathrm{F} 4 / 80^{+}$macrophages. Interestingly, mice that were treated with $\mathrm{RT}$ alone have significantly decreased levels of $\mathrm{CD} 4^{+}$and $\mathrm{CD} 8^{+}$cells, with a moderate decrease in $\mathrm{F} 4 / 80^{+}$macrophages. Control $+\mathrm{CP}$ tumors appeared very similar to those treated with $\mathrm{CP}$ alone, suggesting that $\mathrm{CP}$ was able to increase the level of $\mathrm{CD}^{+}, \mathrm{CD}^{+}$, and $\mathrm{F} 4 / 80^{+}$cells in the tumor. Mice treated with RT $+\mathrm{CP}$ have moderate levels of $\mathrm{CD} 8^{+} \mathrm{T}$ cells (similar to PBS treated mice), decreased levels of $\mathrm{F} 4 / 80^{+}$macrophages, and decreased levels of $\mathrm{CD} 4^{+}$ $\mathrm{T}$ cells.

\section{6. $R T+C P$ Decreases Immunosuppressive MDSCs in the Peripheral Blood}

To investigate the systemic effects of therapeutic intervention, we performed immune analysis studies. E0771 tumors were grown in C57/B16 mice and treated with PBS, control, $\mathrm{CP}$, RT, control $+\mathrm{CP}$, and RT $+\mathrm{CP}$. RT doses were kept consistent with previous studies in Figures 6 and 7. Blood was drawn on days 4 and 9, and peripheral blood mononuclear cells (PBMCs) were analyzed via flow cytometry (Figure 8). While no significant difference was seen in $\mathrm{CD}^{+}$or $\mathrm{CD} 8^{+} \mathrm{T}$ cells, $\mathrm{RT}$ and $\mathrm{RT}+\mathrm{CP}$ significantly reduced macrophages

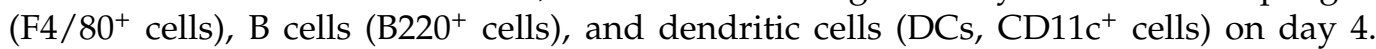
Interestingly, while no therapy was able to suppress myeloid-derived suppressor cells (MDSCs; Ly6G ${ }^{\text {hi }}$ Ly6C ${ }^{\text {int }}$ cells) at day 4, both control $+\mathrm{CP}$ and RT + CP significantly decreased the frequency of circulating MDSCs on day 9. Again, we see that $\mathrm{B}$ cells were suppressed by RT and RT $+\mathrm{CP}$ at day 9 , which we believe can be attributed to their high level of radiosensitivity [30]. 


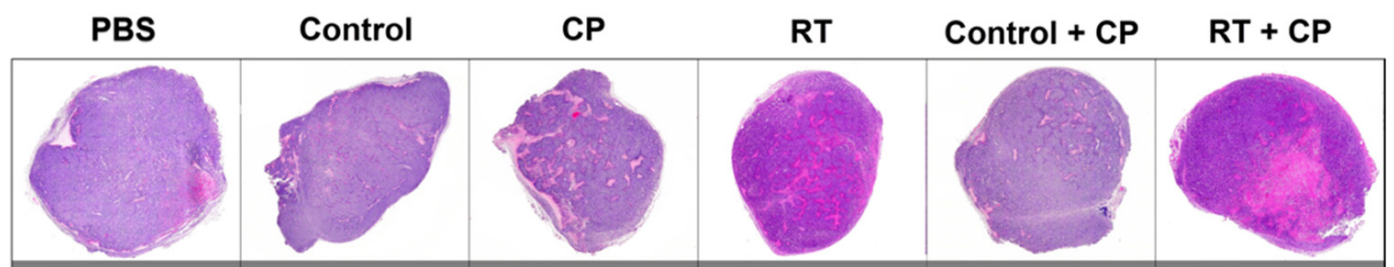

$H \& E$
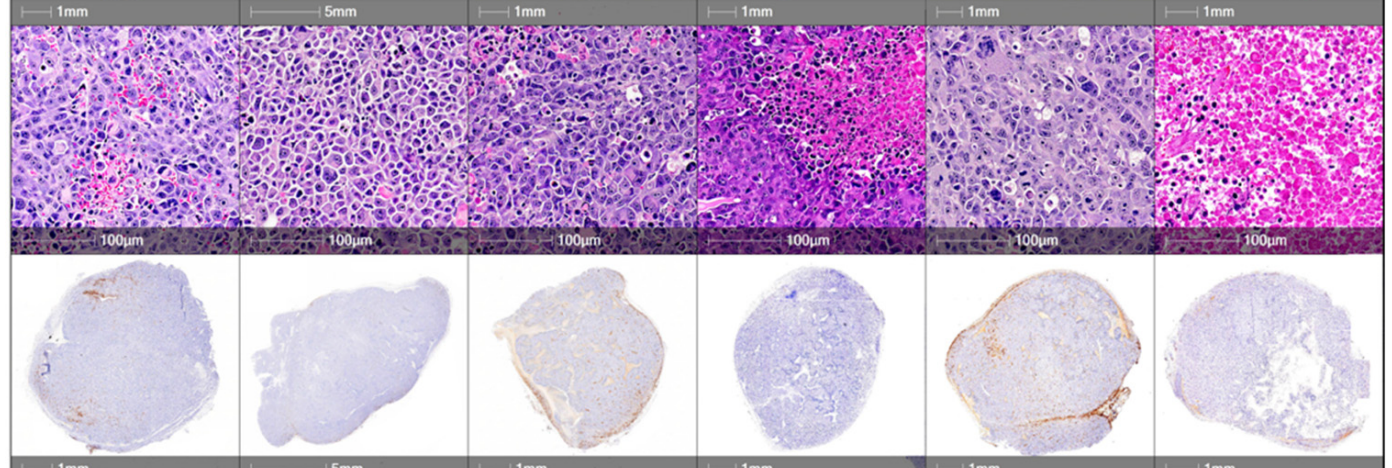

CD4
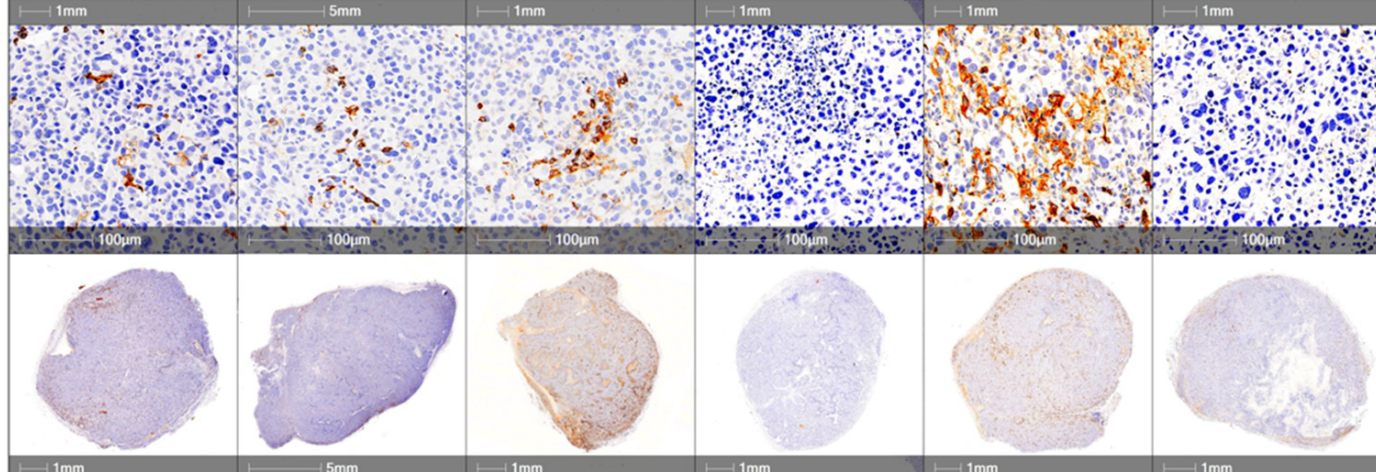

CD8
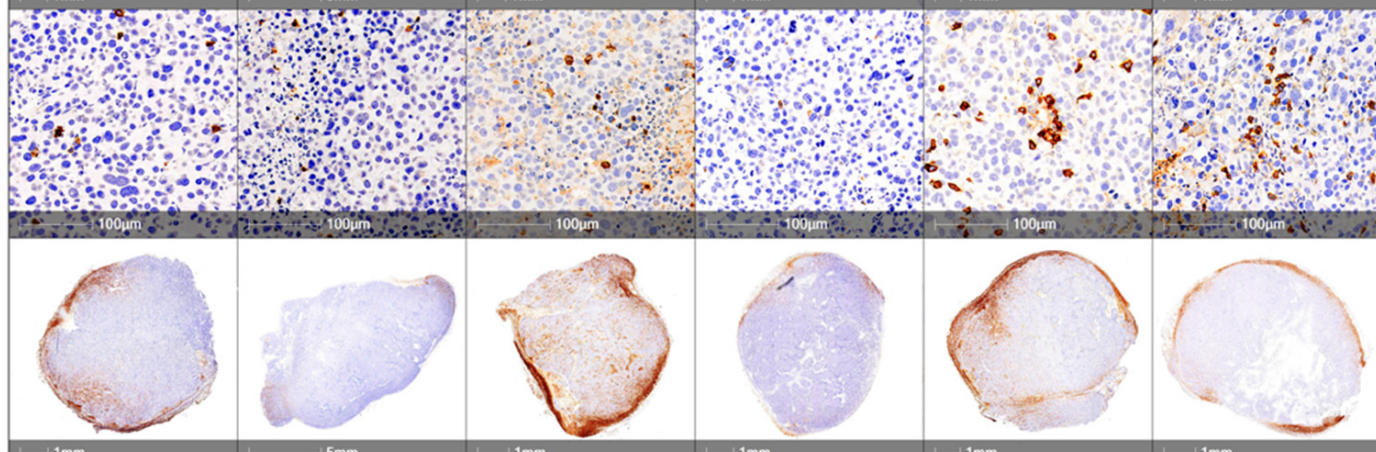

F4/80

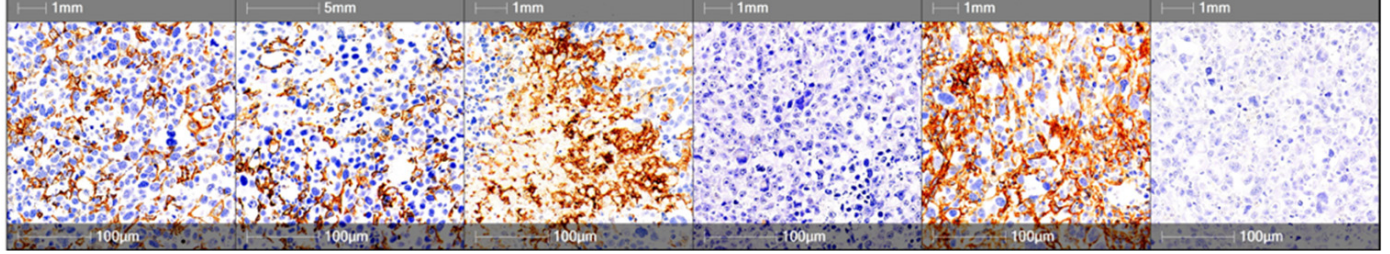

Figure 7. IHC analysis of immune cell infiltrates. C57/Bl6 mice bearing E0771 tumors were treated with PBS, control, CP, RT, control + CP, or RT + CP, and tumors were harvested on day 7. Tumors were sectioned and stained with H\&E, CD4, $\mathrm{CD} 8$, and F4/80 for pathologic analysis. Each representative image shows a whole section of an individual tumor from the given group. 
A
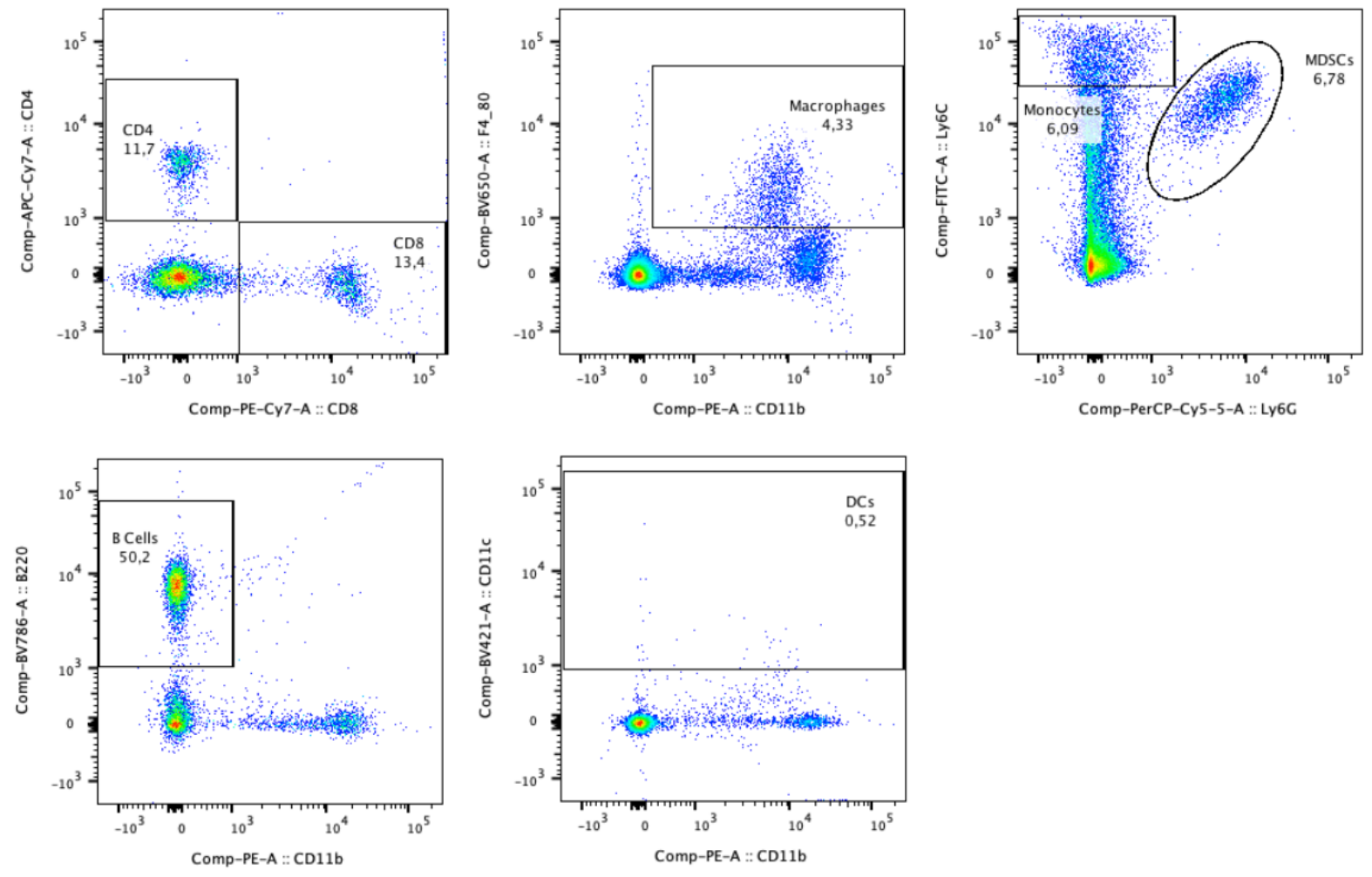

B
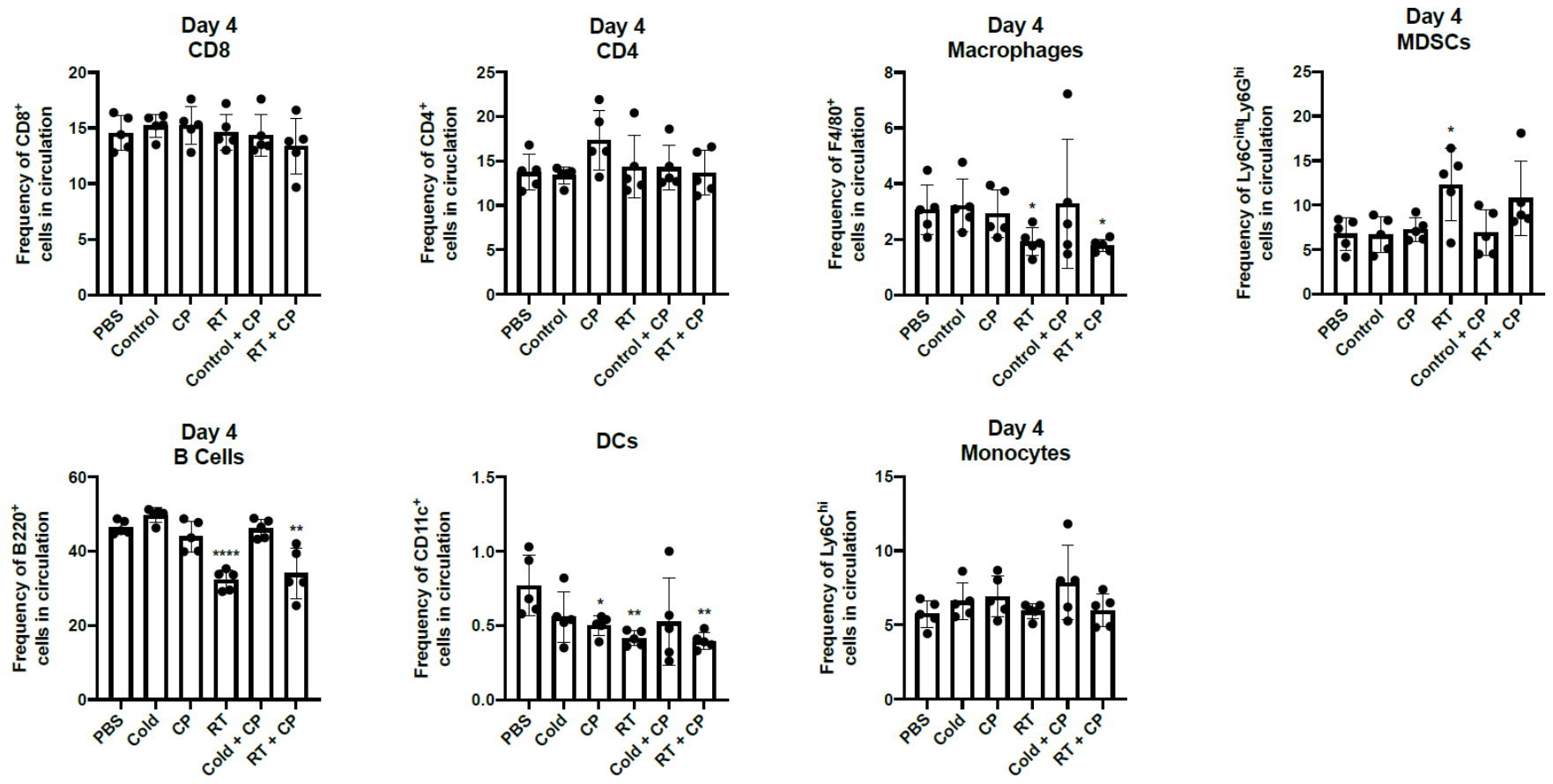

Figure 8. Cont. 
C
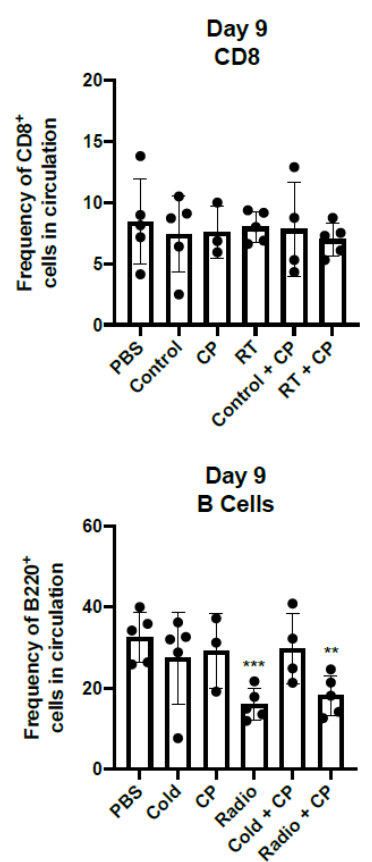

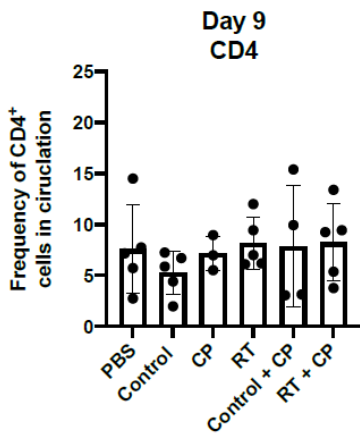

Day 9

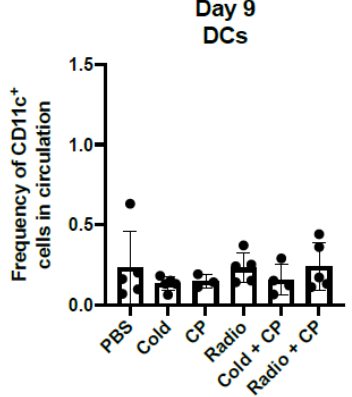

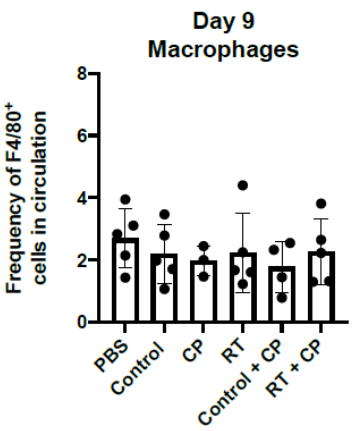

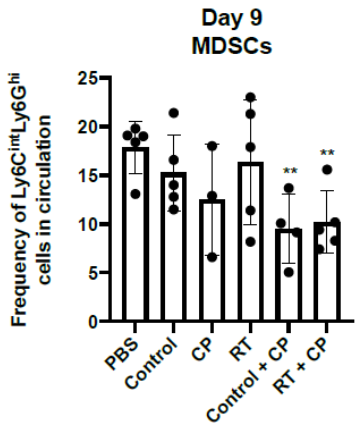

Day 9

Monocytes

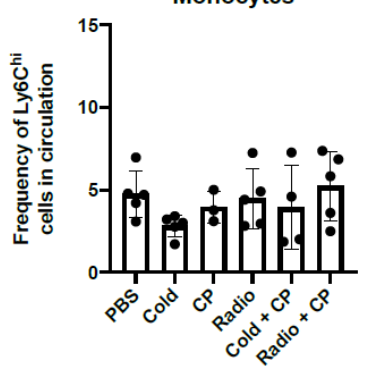

Figure 8. $\mathrm{RT}+\mathrm{CP}$ decreases immunosuppressive MDSCs and B cells in the peripheral blood. C57/B16 mice bearing E0771 tumors were treated with either PBS, Control, CP, RT, Control + CP, or RT + CP. Blood was drawn on days 4 and 9 and analyzed via flow cytometry. (A) Representative flow plots showing the gating strategy for $\mathrm{CD}^{+} \mathrm{T}$ cells, $\mathrm{CD} 8^{+} \mathrm{T}$ cells, $\mathrm{F} 4 / 80^{+}$macrophages, $\mathrm{Ly} 6 \mathrm{C}^{\text {hi }} \mathrm{Ly} 6 \mathrm{G}^{-}$ monocytes, Ly6G $\mathrm{G}^{\text {hi }}$ Ly6C $\mathrm{C}^{\text {int }}$ MDSCs, B220 $0^{+}$B cells, and CD11c ${ }^{+}$DCs. (B) Bar plots showing the frequency of cells in circulation on day 4. (C) Bar plots showing the frequency of cells in circulation on day $9 .{ }^{*} p<0.05 ;{ }^{* *} p<0.01$; $^{* *} p<0.001 ;{ }^{* * *} p<0.0001$.

\section{Discussion}

Clinical studies have detailed the synergistic benefit of combined external beam radiation therapy and immunotherapy [31-36]. Hodge and colleagues demonstrated that external beam radiation of tumors can alter tumor phenotype, rendering it susceptible to immune-mediated killing [37]. While external beam radiation has been a mainstay, first-line therapy for many types of cancer for more than 100 years, it comes with unfavorable side effects such as damage to surrounding tissues and limited utility in metastatic disease. To combat this, researchers have shifted toward the development of internal RT, which can deliver cytotoxic levels of radiation directly to disease sites with a high level of specificity. Indeed, RT can be highly selective not only due to the nature of the targeting vector chosen but also through the choice of radionuclide used. For example, beta-emitting radioisotopes are unable to drive therapeutic response in hypoxic tumors $[38,39]$. In such an instance, the radionuclide can be changed to an alpha emitter, such as actinium-225, for improved efficacy and decreased toxicity to the patient. This allows for the development and utilization of a single tunable probe, which can then be personalized for optimal effectiveness for individual cancers.

In this paper, we have investigated the combined effects of RT with the beta-emitting radionuclide lutetium-177 and CP immunotherapy using anti-PD-L1 and anti-CTLA-4 in an E0771 murine TNBC tumor model. While dual checkpoint blockade has resulted in increased toxicities in patients in clinical trials $[40,41]$, our mice tolerated this treatment very well, with no toxicity seen with $\mathrm{CP}$ or combination regimens. $\mathrm{CP}$ alone showed no survival benefit in our model. The combination of control + CP did show modest benefit, which was likely due to increased $\mathrm{T}$ cell-mediated killing from $\mathrm{CP}$ therapy. However, this benefit was not translated into significant improvements in overall survival, which was only seen with the combination of RT $+\mathrm{CP}$. While studies have documented correlations between increased levels of cytotoxic $\mathrm{T}$ cells and improved overall survival in TNBC 
patients [42], this alone is often insufficient to overcome intrinsic resistance mechanisms and tumor relapse. Indeed, resistance mechanisms are most commonly driven by the immunosuppressive TME, where MDSCs, regulatory T cells (Tregs), and tumor-associated macrophages (TAMs) play a crucial role. Indeed, Tregs are a strong prognostic predictor of therapeutic outcome in TNBC patients [43]. IHC analysis on our treated tumors showed that $\mathrm{RT}+\mathrm{CP}$ is able to decrease TAMs and $\mathrm{CD} 4^{+} \mathrm{T}$ cells. While we did not phenotype the $\mathrm{CD}^{+} \mathrm{T}$ cell population to show they are specifically Tregs, this therapeutic combination has virtually depleted all CD4+ cells, indicating a direct effect on decreasing Tregs (which are always $\mathrm{CD} 4^{+}$).

MDSC frequency is directly correlated with tumor progression, recurrence, poor prognosis, and decreased efficacy of immunotherapies [44]. In our therapeutic combination, we have shown that RT + CP is able to suppress the frequency of MDSCs in peripheral blood, potentially contributing to the observed improved therapeutic efficacy in the form of increased survival. While we do also see the suppression of MDSCs in the control + $\mathrm{CP}$ group, this does not correlate with a benefit in overall survival and may simply be the effect of increase $\mathrm{T}$ cell killing due to $\mathrm{CP}$ administration. Additionally, in TNBC, TAMs have been shown to promote tumor growth and progression while also modulating the levels of PD-L1 expression [45]. In our studies, we have shown that both RT and RT + $\mathrm{CP}$ suppress peripheral macrophages as early as day 4 (Figure 8), suggesting that early treatment with RT aids in alleviating TAM modulation of PD-L1 suppressive functions, although more experiments are required to properly investigate this phenomenon.

Immunotherapies aim to stimulate the immune system to mount a systemic anti-tumor immune response to recognize and destroy tumor cells within the body. Consideration of the abscopal effect and the possibility that RT can truly induce a bona fide anti-tumor immune response greatly expands the breadth of application for this therapeutic platform, as it need not be used solely for primary lesions but can also induce the regression of distant microscopic lesions as well. While this work was completed in a transplantable murine model of TNBC, these studies can be applied to many solid tumor types, increasing the potential translatability of our findings. Additionally, the use of non-radiolabeled BSA was shown to have no influence on therapeutic outcomes or tumor kinetics (as assessed with our control groups). For clinical translation, the BSA derivative can be replaced with the corresponding human serum albumin analogue.

Our studies are limited by the nature of murine hosts and their inability to accurately represent human biology. Indeed, cancer metastasis is a major cause of failed therapeutic intervention and cancer-related deaths [46,47], and our data were conducted in a subcutaneous tumor model representative of primary tumor formation. For enhanced translative capacity, our therapeutic platform should be studied in metastatic and spontaneously arising tumor models to better recapitulate de novo tumor formation in a host. In these models, we would treat the primary tumor and monitor response in metastatic lesions in terms of both the size and number of lesions formed.

\section{Materials and Methods}

\subsection{Cell Lines}

Murine medullary breast adenocarcinoma cells isolated as a spontaneous tumor from a C57 / B16 mouse (E0771; CH3 Biosystems, Amherst, NY, USA) were maintained in Roswell Park Memorial Institute (RPMI) medium supplemented with 10\% FBS, 10 mM HEPES, $200 \mu \mathrm{M}$ geneticin, and $2 \mathrm{mM}$ L-glutamine. Murine mammary gland breast cancer cells isolated as a spontaneous tumor from a Balb/c mouse (4T1; ATCC ${ }^{\circledR}$ CRL2539 ${ }^{\mathrm{TM}}$ ) were maintained in RPMI medium supplemented with 10\% FBS, 2 mM L-glutamine, 100U/mL penicillin and $100 \mu \mathrm{g} / \mathrm{mL}$ streptomycin. All cells were grown at $37^{\circ} \mathrm{C}$ with $5 \% \mathrm{CO}_{2}$.

\subsection{Chemistry General}

Chemicals and reagents for synthesis were purchased from Sigma-Aldrich and Conjuprobe and used without further purification. ${ }^{177} \mathrm{Lu}[\mathrm{Lu}]$ was produced by the McMaster 
Nuclear Reactor (MNR, Hamilton, Ontario, Canada) using the ${ }^{176} \mathrm{Lu}(\mathrm{p}, \gamma)$ reaction and was provided as a solution of $\left[{ }^{177} \mathrm{Lu}\right] \mathrm{LuCl}_{3}$ in $0.01 \mathrm{M} \mathrm{HCl}$. Radio-TLC was performed using a Bioscan AR-2000 imaging scanner (West Vancouver, BC, Canada) on iTLC-SG glass microfiber chromatography paper (SGI0001, Agilent Technologies, Santa Clara, CA, USA) plates using 0.1 M EDTA as the eluent. For each TLC performed, plates were spotted with approximately $2 \mu \mathrm{L}(\approx 3.7 \mathrm{kBq})$ and run for $5 \mathrm{~min}$. MALDI data were obtained using a Bruker Ultraflextreme spectrometer (Billerica, MA, USA).

\subsection{In Vivo Therapy Experiments}

Mice were maintained at the McMaster University Central Animal Facility, and all the procedures were performed in full compliance with the Canadian Council on Animal Care and approved by the Animal Research Ethics Board (Animal Utilization Protocol 17-05-22, January 2020) and the Health Physics Department of McMaster University (Permit KM-1, October 2018). Six- to eight-week-old female C57/Bl6 mice (Charles River Laboratories, Wilmington, MA, USA) were used to implant $5 \times 10^{6}$ E0771 cells subcutaneously on the left flank. Mice were weighed and all were found to be approximately $20 \mathrm{~g}$ in size. Mice were housed in groups, 5/cage, fed a normal diet, and kept at room temperature. To minimize experimental variability, low-passage E0771 cells were used for subcutaneous injections. Twelve days after injection, the tumors reached treatable average tumor volume (50-100 $\mathrm{mm}^{3}$ ). Mice were blindly randomized prior to the start of treatment, but not blinded once treatments commenced. In experimental groups receiving control treatment, mice were treated on day 1 and day 5 with DNP-DOTA-BSA $(100 \mu \mathrm{g} / 50 \mu \mathrm{L}$ PBS, intratumorally). Experimental groups receiving RT treatment were treated on day 1 and day 5 with $\approx 4.44 \mathrm{MBq}$ of ${ }^{177} \mathrm{Lu}$-DNP-DOTA-BSA (100 $\mu \mathrm{g} / 50 \mu \mathrm{L}$ PBS, intratumorally). Experimental groups receiving CP were treated with $\alpha$-CTLA-4 (BioXCell, BE0131) and $\alpha$-PD-L1 (BioXCell, BE101) antibodies (200 $\mu \mathrm{g} / 200 \mu \mathrm{L}$ PBS each, intraperitoneally) starting on day 3 , every 3 days until mice reached endpoint or a total of 10 doses had been given. For all mouse studies, tumors were measured every 2-3 days, and mice having a tumor volume of $1000 \mathrm{~mm}^{3}$ were classified as endpoint.

\subsection{Radiochemistry Methods}

To a solution of tetrazine, a small molecule $(100 \mu \mathrm{g}, 48.0 \mathrm{nmol})$ in $100 \mu \mathrm{L}$ of $0.1 \mathrm{M}$

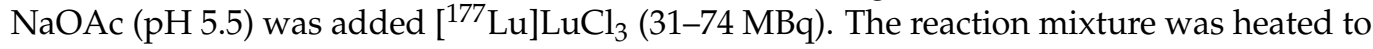
$60^{\circ} \mathrm{C}$ for $5 \mathrm{~min}$, at which point a radio-TLC (cellulose/silica plate) was run in $0.1 \mathrm{M}$ EDTA solution. The radiochemical yield of the reaction was determined to be $>99 \%$ with $>99 \%$ radiochemical purity. The radiolabelled tetrazine was added to a solution of TCO-BSA $(2 \mathrm{mg} / \mathrm{mL})$ in saline at room temperature for $10 \mathrm{~min}$. The reaction was added to a $50 \mathrm{kDa}$ spin filter and centrifuged at $4000 \mathrm{rpm}$ for $10 \mathrm{~min}$, which had been previously activated with $1.00 \mathrm{~mL}$ of saline. The supernatant was washed twice with $1 \mathrm{~mL}$ of sterile saline and centrifuged as stated above, which was followed by resuspension in sterile saline for injection. The conjugation efficiency of the reaction was $46 \pm 5 \%(n=3)$.

\subsection{Autoradiography}

C57Bl/6 mice bearing an E0771 flank tumor were administered a single dose of radiolabeled BSA $(0.15-0.33 \mathrm{MBq} / 100 \mu \mathrm{g}$, intratumorally) on day 12 of growth when the tumors were palpable $\left(\approx 100 \mathrm{~mm}^{3}\right)$. The mice were sacrificed after 24,72 , or $120 \mathrm{~h}(\mathrm{n}=3)$, at which point the tumors were harvested, placed on a cryomold, and submerged in optimal cutting temperature compound. Then, the cryomold was wrapped in plastic wrap and flash frozen in liquid nitrogen for $15 \mathrm{~s}$. The tumors were sent for analysis, where they were sliced and placed on a phosphor screen for 10 days.

\subsection{Biodistribution Studies}

Female, 5-6-week-old Balb/c mice ordered from Charles River Laboratory (Kingston, NY) were inoculated with $1 \times 10^{6} 4 \mathrm{~T} 1$ breast cancer cells in the right flank. On day 7 of 
growth, the mice were administered radiolabeled BSA $(0.07-0.33 \mathrm{MBq} / 100 \mu \mathrm{g}$, intratumorally). At 72 and $120 \mathrm{~h}$ post-injection ( $\mathrm{n}=3$ per time point), mice were anesthetized with $3 \%$ isoflurane and euthanized by cervical dislocation. Blood, adipose, adrenals, bone, brain, gall bladder, heart, kidneys, large intestine and caecum (with contents), liver, lungs, pancreas, skeletal muscle, small intestine (with contents), spleen, stomach (with contents), thyroid/trachea, urine + bladder, tumor, and tail were collected, weighed, and counted in a gamma counter. Decay correction was used to normalize organ activity measurements to time of dose preparation for data calculations with respect to injected dose (i.e., \%ID/g).

\subsection{Histology}

Non-radioactive tumors were resected on day 7 , fixed in $10 \%$ formalin for $48 \mathrm{~h}$, and then transferred to $70 \%$ ethanol for immediate histological processing. Radioactive tumors were resected on day 7 , fixed in $10 \%$ formalin, decayed for 3 months, and then transferred to $70 \%$ ethanol for histological processing. Tumor tissue was embedded in paraffin, and $4-\mu \mathrm{m}$ sections were prepared. Tissue sections were processed for hematoxylin staining and IHC using Automated Leica Bond Rx stainer with Bond Refine Polymer Detection kit (Leica, DS9800). All antibodies were diluted in IHC/ISH Super Blocker (Leica, PV6199). Primary antibodies and working dilutions using HIER Retrieval Buffer 2 (Leica, AR9640) were as follows: CD3 (1:150; Abcam, ab16669), CD4 (1:800; eBio, 14-9766), and CD8a (1:1000; eBio, 14-0808). For F4/80 (1:500; AbD Serotec, MCA497R), an Enzyme 1 pre-treatment was performed before staining with antibody (AR9551). Antibodies CD4, CD8a, CD19, and F4/80 all required a secondary antibody before polymer detection using Rabbit anti-rat (Vector labs BA4001) at a dilution of 1:100. Immunohistochemistry slides were digitalized using the Olympus VS120-L100-W automated slide scanner (Shinjuku, Tokyo, Japan). They were batch-scanned on the brightfield setting at $20 \times$ magnification. The color camera used was the Pike 505C VC50.

\subsection{Flow Cytometry Analysis}

First, $150 \mu \mathrm{L}$ blood was collected from the periorbital sinus. Red blood cells from all samples were lysed using ACK buffer. The PBMCs were treated with anti-CD16/CD32 (Fc block) and surface stained with fluorescently conjugated antibodies for FVS (BD Biosciences, \#564406), CD4 (BD Biosciences, \#561830), CD8 (BD Biosciences, \#563046), CD11b (BD Biosciences, \#553311), Ly6C (BD Biosciences, \#553104), Ly6G (BD Biosciences, \#560602), and F4/80 (BD Biosciences, \#743282). An LSRFortessa flow cytometer (BD Biosciences, Mississauga, ON, Canada) with FACSDiva software (BD Biosciences, Mississauga, ON, Canada)) was used for data acquisition and FlowJo (Ashland, OR, USA) Mac, version 10.0 software was used for data analysis.

\subsection{Statistical Analysis}

For each statistical analysis used, normality of the distributions and variance assumptions were tested before running the statistical analyses. Multiple t-tests were used to determine the statistical significance of the differences in means. The log-rank Mantel-Cox test and the Gehan-Breslow-Wilcoxon test were used to determine statistical significance for the difference in Kaplan-Meier survival curves between treatments. All the tests were two-sided. The null hypothesis was rejected for $p$-values less than 0.05 . All data analyses were carried out using GraphPad Prism (San Diego, CA, USA).

Supplementary Materials: The following are available online at https:/ / www.mdpi.com/article/ 10.3390/ijms22094843/s1, Figure S1: MALDI-MS confirms conjugation of TCO to BSA, Figure S2: Biodistribution studies show retention of RT in the tumor, Figure S3: Preliminary dose optimization studies for RT regimens, Figure S4: Dose optimization studies for RT regimens, Table S1: Biodistribution studies. \%ID/g values for the complete tissue list, for each mouse ( $\mathrm{n}=3$ per timepoint), Table S2: Biodistribution studies, intravenous administration. \%ID/g values for the complete tissue list, for each mouse ( $\mathrm{n}=3$ per timepoint). 
Author Contributions: Conceptualization, A.V., S.R., K.M. and J.V.; Methodology, A.V. and S.R.; Investigation, A.V., S.R., N.M. and N.E.-S.; Writing-Original Draft, A.V. and S.R.; Writing-Review and Editing, A.V., S.R., N.M., N.E.-S., K.M. and J.V.; Funding Acquisition, K.M. and J.V.; Resources, K.M. and J.V.; Supervision, K.M. and J.V. All authors have read and agreed to the published version of the manuscript.

Funding: This work was sponsored by operating grants from the Canadian Cancer Society Research Institute; grant \#706280 and \#7038587.

Institutional Review Board Statement: Animal studies were conducted according to the guidelines of the Canadian Council on Animal Care, and approved by the Animal Research Ethics Board (Animal Utilization Protocol 17-05-22, January 2020) and the Health Physics Department of McMaster University Central Animal Facility (Radioactive Permit KM-1, October 2018).

Informed Consent Statement: Not applicable.

Data Availability Statement: All data is contained within this manuscript and within the supplemental data file.

Acknowledgments: Alyssa Vito was the recipient of the Vanier Canada Graduate Scholarship. The authors would like to acknowledge the core histology facility at McMaster University for their work processing histologic samples and the MPIC Facility for scanning of IHC slides.

Conflicts of Interest: The authors declare no conflict of interest. The funders had no role in the design of the study; in the collection, analyses, or interpretation of data; in the writing of the manuscript, or in the decision to publish the results.

\section{References}

1. Ferlay, J.; Colombet, M.; Soerjomataram, I.; Mathers, C.; Parkin, D.M.; Pineros, M.; Znaor, A.; Bray, F. Estimating the global cancer incidence and mortality in 2018: GLOBOCAN sources and methods. Int. J. Cancer 2019, 144, 1941-1953. [CrossRef] [PubMed]

2. Wang, X.; Qi, Y.; Kong, X.; Zhai, J.; Li, Y.; Song, Y.; Wang, J.; Feng, X.; Fang, Y. Immunological therapy: A novel thriving area for triple-negative breast cancer treatment. Cancer Lett. 2019, 442, 409-428. [CrossRef] [PubMed]

3. Stagg, J.; Allard, B. Immunotherapeutic approaches in triple-negative breast cancer: Latest research and clinical prospects. Ther. Adv. Med. Oncol. 2013, 5, 169-181. [CrossRef] [PubMed]

4. Dawson, S.; Provenzano, E.; Caldas, C. Triple negative breast cancers: Clinical and prognostic implications. Eur. J. Cancer 2009, 45, 27-40. [CrossRef]

5. Robert, C. A decade of immune-checkpoint inhibitors in cancer therapy. Nat. Commun. 2020, 11, 1-3. [CrossRef]

6. Darvin, P.; Toor, S.M.; Nair, V.S.; Elkord, E. Immune checkpoint inhibitors: Recent progress and potential biomarkers. Exp. Mol. Med. 2018, 50, 1-11. [CrossRef]

7. Nowicki, T.S.; Hu-Lieskovan, S.; Ribas, A. Mechanisms of Resistance to PD-1 and PD-L1 Blockade. Cancer J. 2018, $24,47-53$. [CrossRef]

8. Mahoney, K.M.; Rennert, P.D.; Freeman, G.J. Combination cancer immunotherapy and new immunomodulatory targets. Nat. Rev. Drug Discov. 2015, 14, 561-584. [CrossRef]

9. Melero, I.; Berman, D.M.; Aznar, M.A.; Korman, A.J.; Gracia, J.L.P.; Haanen, J.B.A.G. Evolving synergistic combinations of targeted immunotherapies to combat cancer. Nat. Rev. Cancer 2015, 15, 457-472. [CrossRef]

10. Kalbasi, A.; June, C.H.; Haas, N.; Vapiwala, N. Radiation and immunotherapy: A synergistic combination. J. Clin. Investig. 2013, 123, 2756-2763. [CrossRef]

11. Afshar, S.F.; Zawaski, J.A.; Inoue, T.; Rendon, D.A.; Zieske, A.W.; Punia, J.N.; Sabek, O.M.; Gaber, M.W. Investigating the Abscopal Effects of Radioablation on Shielded Bone Marrow in Rodent Models Using Multimodality Imaging. Radiat. Res. 2017, 188, 56-65. [CrossRef] [PubMed]

12. Mole, R.H. Whole Body Irradiation-Radiobiology or Medicine? Br. J. Radiol. 1953, 26, 234-241. [CrossRef] [PubMed]

13. Larson, S.M.; Carrasquillo, J.A.; Cheung, N.-K.V.; Press, O.W. Radioimmunotherapy of human tumours. Nat. Rev. Cancer 2015, 15, 347-360. [CrossRef]

14. Sharkey, R.M.; Goldenberg, D.M. Cancer radioimmunotherapy. Immunotherapy 2011, 3, 349-370. [CrossRef]

15. Choi, J.; Beaino, W.; Fecek, R.J.; Fabian, K.P.; Laymon, C.M.; Kurland, B.F.; Storkus, W.J.; Anderson, C.J. Combined VLA4-Targeted Radionuclide Therapy and Immunotherapy in a Mouse Model of Melanoma. J. Nucl. Med. 2018, 59, 1843-1849. [CrossRef] [PubMed]

16. Ho, A.Y.; Barker, C.A.; Ba, B.B.A.; Powell, S.N.; Hu, Z.I.; Gucalp, A.; Lebron-Zapata, L.; Wen, H.Y.; Kallman, C.; D’ Agnolo, A.; et al. A phase 2 clinical trial assessing the efficacy and safety of pembrolizumab and radiotherapy in patients with metastatic triple-negative breast cancer. Cancer 2019, 126, 850-860. [CrossRef]

17. Bakker, R.C.; Lam, M.G.; Van Nimwegen, S.A.; Rosenberg, A.J.; Van Es, R.J.; Nijsen, J.F.W. Intratumoral treatment with radioactive beta-emitting microparticles: A systematic review. J. Radiat. Oncol. 2017, 6, 323-341. [CrossRef] 
18. Ulrich, G.; Dudeck, O.; Furth, C.; Ruf, J.; Grosser, O.S.; Adolf, D.; Stiebler, M.; Ricke, J.; Amthauer, H. Predictive Value of Intratumoral 99mTc-Macroaggregated Albumin Uptake in Patients with Colorectal Liver Metastases Scheduled for Radioembolization with 90Y-Microspheres. J. Nucl. Med. 2013, 54, 516-522. [CrossRef]

19. Caraceni, P.; Tufoni, M.; Bonavita, M.E. Clinical use of albumin. High Speed Blood Transfus. Equip. 2013, 11, s18-s25.

20. Garin, E.; Palard, X.; Rolland, Y. Personalised Dosimetry in Radioembolisation for HCC: Impact on Clinical Outcome and on Trial Design. Cancers 2020, 12, 1557. [CrossRef]

21. Rathmann, S. Development of a Versatile Platform for Combination Targeted Radionuclide and Immune Cell Recruitment Therapies Using Bio-Orthogonal Chemistry; McMaster University: Hamilton, ON, Canada, 2020.

22. Vilchis-Juárez, A.; Ferro-Flores, G.; Santos-Cuevas, C.L.; Morales-Avila, E.; Ocampo-García, B.; Díaz-Nieto, L.; Luna-Gutiérrez, M.; Jiménez-Mancilla, N.P.; Pedraza-Lopez, M.; Gómez-Oliván, L.M. Molecular Targeting Radiotherapy with Cyclo-RGDfK(C) Peptides Conjugated to 177Lu-Labeled Gold Nanoparticles in Tumor-Bearing Mice. J. Biomed. Nanotechnol. 2014, 10, 393-404. [CrossRef] [PubMed]

23. Hoskin, P.J.; Hopkins, K.; Misra, V.; Holt, T.; McMenemin, R.; Dubois, D.; McKinna, F.; Foran, B.; Madhavan, K.; MacGregor, C.; et al. Effect of Single-Fraction vs Multifraction Radiotherapy on Ambulatory Status Among Patients With Spinal Canal Compression from Metastatic Cancer. JAMA 2019, 322, 2084-2094. [CrossRef]

24. Palayoor, S.T.; John-Aryankalayil, M.; Makinde, A.Y.; Falduto, M.T.; Magnuson, S.R.; Coleman, C.N. Differential Expression of Stress and Immune Response Pathway Transcripts and miRNAs in Normal Human Endothelial Cells Subjected to Fractionated or Single-Dose Radiation. Mol. Cancer Res. 2014, 12, 1002-1015. [CrossRef]

25. Schaue, D.; Ratikan, J.A.; Iwamoto, K.S.; McBride, W.H. Maximizing Tumor Immunity With Fractionated Radiation. Int. J. Radiat. Oncol. 2012, 83, 1306-1310. [CrossRef] [PubMed]

26. Cyprian, F.S.; Akhtar, S.; Gatalica, Z.; Vranic, S. Targeted immunotherapy with a checkpoint inhibitor in combination with chemotherapy: A new clinical paradigm in the treatment of triple-negative breast cancer. Bosn. J. Basic Med. Sci. 2019, 19, 227-233. [CrossRef]

27. Schmid, P.; Adams, S.; Rugo, H.S.; Schneeweiss, A.; Barrios, C.H.; Iwata, H.; Diéras, V.; Hegg, R.; Im, S.A.; Shaw Wright, G.; et al. Atezolizumab and Nab-Paclitaxel in Advanced Triple-Negative Breast Cancer. N. Engl. J. Med. 2018, 379, 2108-2121. [CrossRef] [PubMed]

28. Dill, E.A.; Gru, A.A.; Atkins, K.A.; Friedman, L.A.; Moore, M.E.; Bullock, T.N.; Cross, J.V.; Dillon, P.M.; Mills, A.M. PD-L1 Expression and Intratumoral Heterogeneity Across Breast Cancer Subtypes and Stages. Am. J. Surg. Pathol. 2017, 41, 334-342. [CrossRef]

29. Vikas, P.; Borcherding, N.; Zhang, W. The clinical promise of immunotherapy in triple-negative breast cancer. Cancer Manag. Res. 2018, 10, 6823-6833. [CrossRef]

30. Anderson, R.E.; Williams, W.L. Radiosensitivity of T and B lymphocytes. V. Effects of whole body irradiation on numbers of recirculating T cells and sensitization to primary skin grafts in mice. Am. J. Pathol. 1977, 89, 367-378.

31. Finkelstein, S.E.; Fishman, M. Clinical opportunities in combining immunotherapy with radiation therapy. Front. Oncol. 2012, 2, 169. [CrossRef]

32. Hodge, J.W.; Guha, C.; Neefjes, J.; Gulley, J.L. Synergizing radiation therapy and immunotherapy for curing incurable cancers. Opportunities and challenges. Oncology 2008, 22, 1064-1084.

33. Schiavone, M.B.; Broach, V.; Shoushtari, A.N.; Carvajal, R.D.; Alektiar, K.; Kollmeier, M.A.; Abu-Rustum, N.R.; Leitao, M.M. Combined immunotherapy and radiation for treatment of mucosal melanomas of the lower genital tract. Gynecol. Oncol. Rep. 2016, 16, 42-46. [CrossRef]

34. Ferrara, T.A.; Hodge, J.W.; Gulley, J.L. Combining radiation and immunotherapy for synergistic antitumor therapy. Curr. Opin. Mol. Ther. 2009, 11, 37-42.

35. Finkelstein, S.E.; Salenius, S.; Mantz, C.A.; Shore, N.D.; Fernandez, E.B.; Shulman, J.; Myslicki, F.A.; Agassi, A.M.; Rotterman, Y.; Devries, T.; et al. Combining Immunotherapy and Radiation for Prostate Cancer. Clin. Genitourin. Cancer 2015, 13, 1-9. [CrossRef]

36. Hiniker, S.M.; Knox, S.J. Immunotherapy and Radiation. Semin. Oncol. 2014, 41, 702-713. [CrossRef]

37. Chakraborty, M.; Abrams, S.I.; Coleman, C.N.; Camphausen, K.; Schlom, J.; Hodge, J.W. External Beam Radiation of Tumors Alters Phenotype of Tumor Cells to Render Them Susceptible to Vaccine-Mediated T-Cell Killing. Cancer Res. 2004, 64, 4328-4337. [CrossRef]

38. Saha, G.B. Physics and Radiobiology of Nuclear Medicine; Springer Science \& Business Media: Berlin/Heidelberg, Germany, 2013; ISBN 9781461440123.

39. Marcu, L.; Bezak, E.; Allen, B.J. Global comparison of targeted alpha vs targeted beta therapy for cancer: In vitro, in vivo and clinical trials. Crit. Rev. Oncol. 2018, 123, 7-20. [CrossRef] [PubMed]

40. Villadolid, J.; Amin, A. Immune checkpoint inhibitors in clinical practice: Update on management of immune-related toxicities. Transl. Lung Cancer Res. 2015, 4, 560-575.

41. Johnson, D.B.; Reynolds, K.L.; Sullivan, R.J.; Balko, J.M.; Patrinely, J.R.; Cappelli, L.C.; Naidoo, J.; Moslehi, J.J. Immune checkpoint inhibitor toxicities: Systems-based approaches to improve patient care and research. Lancet Oncol. 2020, 21, e398-e404. [CrossRef]

42. Gao, G.; Wang, Z.; Qu, X.; Zhang, Z. Prognostic value of tumor-infiltrating lymphocytes in patients with triple-negative breast cancer: A systematic review and meta-analysis. BMC Cancer 2020, 20, 1-15. [CrossRef] [PubMed] 
43. Lee, S.; Cho, E.Y.; Park, Y.H.; Ahn, J.S.; Im, Y.-H. Prognostic impact of FOXP3 expression in triple-negative breast cancer. Acta Oncol. 2012, 52, 73-81. [CrossRef]

44. Kang, C.; Jeong, S.-Y.; Song, S.Y.; Choi, E.K. The emerging role of myeloid-derived suppressor cells in radiotherapy. Radiat. Oncol. J. 2020, 38, 1-10. [CrossRef] [PubMed]

45. Santoni, M.; Romagnoli, E.; Saladino, T.; Foghini, L.; Guarino, S.; Capponi, M.; Giannini, M.; Cognigni, P.D.; Ferrara, G.; Battelli, N. Triple negative breast cancer: Key role of Tumor-Associated Macrophages in regulating the activity of anti-PD-1/PD-L1 agents. Biochim. Biophys. Acta (BBA)-Bioenerg. 2018, 1869, 78-84. [CrossRef]

46. Hanahan, D.; Weinberg, R.A. Hallmarks of Cancer: The Next Generation. Cell 2011, 144, 646-674. [CrossRef] [PubMed]

47. Chaffer, C.L.; Weinberg, R.A. A Perspective on Cancer Cell Metastasis. Science 2011, 331, 1559-1564. [CrossRef] [PubMed] 